\title{
Organizações comunicacionais e o binômio imitação-inovação ${ }^{1}$
}

\author{
Communication organizations \\ and the imitation-innovation binomial
}

Organizaciones comunicacionales y el binomio imitación-innovación

\section{Gino Giacomini Filho}

- Doutor e livre-docente pela Escola de Comunicações e Artes da Universidade de São Paulo (ECA-USP)

- Coordenador do Programa de Mestrado em Comunicação da Universidade Municipal de São Caetano do Sul (USCS)

- Professor da USCS (mestrado e graduação) e da ECA-USP (graduação)

- Autor dos livros Consumidor versus propaganda (Summus, 2008),

Ecopropaganda (Senac, 2004) e Meio ambiente \& consumismo (Senac, 2008)

- giacomin@usp.br

1 Projeto apoiado pela Fapesp. Colaboração de Ana Beatriz Cajado, aluna de iniciação científica (bolsa da Universidade Municipal de São Caetano do Sul - USCS). 
O artigo objetiva analisar a prática da imitação-inovação no contexto organizacional, tendo como foco o campo da comunicação e, ainda, propor um modelo teórico para essa prática. Trata-se de um estudo exploratório que faz uso de referencial teórico nos eixos teóricos de inovação, imitação, organizações e comunicação social. Resultou na apresentação de um modelo de inovação - inovação intrínseca, inovação percebida e inovação conjugada - e de um modelo de imitação - imitação intrínseca, imitação percebida e imitação conjugada.

PALAVRAS-CHAVE: ORGANIZAÇÕES COMUNICACIONAIS • INOVAÇÃO • IMITAÇÃO • COMUNICAÇÃO

\section{Abstract}

This text analyzes the imitation-innovation practice in the organizational context and focuses on the field of communication, also proposing a theoretical model for this practice. It concerns an exploratory study that uses theoretical references in the innovation, imitation, organization and communication fields. It presents as a result an innovation model - intrinsic innovation, perceived innovation, conjugated innovation - and an imitation model - intrinsic imitation, perceived imitation, conjugated imitation.

KEYWORDS: COMMUNICARION ORGANIZATIONS • INNOVATION • IMITATION • COMMUNICATION

\section{Resumen}

El objetivo de este artículo es analizar la práctica de la imitación-innovación en el contexto organizacional, centrándose en el ámbito de la comunicación, así como proponer un modelo teórico para esta práctica. Se trata de un estudio exploratorio que utiliza referencias de los ejes teóricos de la innovación, la imitación, las organizaciones y la comunicación social. Como resultado se presenta un modelo de innovación (innovación intrínseca, innovación percibida e innovación conjugada) y un modelo de imitación (imitación intrínseca, imitación percibida e imitación conjugada).

PALABRAS CLAVE: ORGANIZACIONES COMUNICACIONALES • INNOVACIÓN • IMITACIÓN • COMUNICACIÓN 


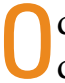
conceito de inovação tem sido bastante trabalhado nas diversas áreas do conhecimento, inclusive no âmbito da comunicação enquanto difusão de inovações (ROGERS, 2003) ou no uso de novos paradigmas tecnológicos e de conteúdo, caso dos processos de criatividade que frequentam os trabalhos publicitários (BERTOMEU, 2002). No entanto, as práticas imitativas, no geral e na comunicação, não desfrutam dessa ampla reflexão, talvez por inocularem fatores restritivos no plano legal, concorrencial e social (SCHNAARS, 1997; ASTOUS GARGOURI, 2001; CARRASCOZA, 2008).

A esse quadro soma-se a importância das organizações no exercício de atividades imitativas e inovadoras em comunicação, o que conduz ao objetivo deste trabalho, de propor um modelo teórico para a prática da imitação-inovação no contexto organizacional tendo como foco o campo da comunicação.

A área de comunicação social depara-se, continuamente, com indagações sobre práticas imitativas, notadamente de seus conteúdos e padrões estéticos. Muitos anúncios publicitários, sites, programas na mídia, filmes, campanhas promocionais são apontados como produtos comunicacionais que imitam outros, algo que se relaciona com a responsabilidade social das organizações atuantes na comunicação dado o potencial de dano social que tal prática oferece (DAY, 1991).

No entanto, para Osório (1992), inovação e imitação complementam-se, uma vez que toda inovação considera modelos anteriores para sua efetivação, de forma que, ao discutir a imitação ou o grau imitativo da comunicação, necessariamente nos remetemos ao seu par, a inovação, pois inovação e imitação imbricam-se num binômio que se completa.

O conceito de inovação no campo organizacional apresenta intensa contribuição acadêmica, caso das correntes teóricas que consideram a inovação como algo intrinsecamente novo ou que a consideram como algo apropriado como novo, diferentemente do escopo imitativo que carece de uma sistematização notadamente ligada ao campo da comunicação.

Portanto, verifica-se a necessidade de proposição de modelos teóricos que contemplem o binômio imitação-inovação no contexto organizacional concernente às práticas da comunicação social, o que leva ao questionamento central deste trabalho: qual modelo teórico poderia abrigar a prática da imitação-inovação no âmbito da comunicação no contexto organizacional?

Tal problema de pesquisa é norteado pelos aspectos processuais e de conteúdo da comunicação das organizações, conteúdos esses presentes em seus produtos comunicacionais. Os produtos comunicacionais (campanhas promocionais, jornais, websites etc.) podem ser contextualizados nas organizações que utilizam ou oferecem serviços de comunicação, sejam elas especializadas ou não no setor (MATTELART, 2002). Nesse sentido, as estratégias 
e a cultura dessas organizações contam muito para o âmbito da imitaçãoinovação no que se refere tanto à gestão quanto a seus produtos comunicacionais (ALENCAR, 1995).

Para atingir os propósitos apresentados, o presente artigo, de cunho exploratório, faz uso de referencial teórico nos eixos teóricos de inovação, imitação, comunicação social e organizacional.

\section{INOVAÇÃO E IMITAÇÃO}

Para Osório (1992), a inovação dificilmente significa ruptura, mas um novo padrão resultante do aperfeiçoamento de modelos anteriores. Modelos antecedentes também são referências para a criatividade, embora Alencar (1995) sustente que este termo seja mais bem aplicável em relação a indivíduos (criativos), enquanto inovação às organizações. Como a criatividade das pessoas colabora com a inovação nas empresas e instituições, esses termos podem ser vistos como correlatos. Prevê ainda a autora a convivência de dois tipos básicos de inovações: técnicas (novo produto ou serviço) e administrativas (sistema social da organização ou método de trabalho), tipos esses presentes nas organizações comunicacionais respectivamente na forma de produtos e processos de gestão da comunicação.

A imitação também pode ser vista como parte estrutural da inovação e viceversa (OSÓRIO, 1992). É possível considerar que a inovação inocula a imitação, a qual, neste contexto, pode ser vista como algo positivo e socialmente aceitável. A imitação pode ser um estágio natural da inovação (GANZ, 1980), no sentido de que uma inovação apenas poderá ser apropriada ou utilizada por pessoas se estas puderem reproduzi-la ou cuja apropriação redunde em outras inovações (WHITE, 2001). Ganz indica vários estudiosos que concebem a imitação como sinônimo de difusão, em que uma invenção ou inovação é naturalmente seguida pela imitação para ser reproduzida no meio social, científico e corporativo.

Portanto, procedimentos de imitação e inovação fazem parte das organizações, inclusive as que exercitam a comunicação. O comportamento imitativo ou inovador das organizações comunicacionais mostra que tais procedimentos não são meramente casuais ou intuitivos, pois possuem vínculos com a cultura e estratégias organizacionais.

\section{IMITAÇÃO NA CULTURA E ESTRATÉGIA ORGANIZACIONAL}

Emissoras de televisão, editoras, veículos jornalísticos, assessorias de comunicação, empresas promocionais, agências de publicidade, entidades corporativas de comunicação são exemplos de organizações comunicacionais ou in- 
dústria da comunicação ambientada em um mercado. Oferecem a produção, intermediação, representação e gestão de produtos, serviços e atividades de comunicação informativa, institucional e persuasiva (MATTELART, 2002).

Tal como uma instituição de qualquer setor, uma organização comunicacional apresenta características empreendedoras alinhadas a uma cultura organizacional. Robbins (1998) elenca algumas características da cultura organizacional: inovação e risco, orientação a resultados, agressividade, estabilidade, entre outros. Essas características atuam decisivamente na forma como são concebidos os produtos comunicacionais, tais como um jornal impresso, revista virtual, filme ou anúncio publicitário; assim, o contexto oferecido pela cultura de uma organização comunicacional empresta, para seus produtos e processos, valores e crenças coletivas e individuais, inclusive os relativos a práticas de imitação e inovação.

Utterback (1996) cita o caso histórico do mercado de máquina de escrever no final do século XIX, em que empresas copiavam os lançamentos de suas concorrentes em ritmo acelerado. O autor mostra ainda que ex-funcionários eram também responsáveis por muitos dos processos imitativos organizacionais; exemplificou com as constatações de Eastman de que funcionários do alto escalão estavam repassando tecnologia do seu processo fotográfico a terceiros.

Robbins (1998) conclui que as decisões de caráter ético e moral em uma organização decorrem tanto de posturas individuais como coletivas contextualizadas no ambiente organizacional e que funcionários corretos podem ser corrompidos pelo ambiente da organização ao permitir ou encorajar práticas não-éticas. Nesse sentido, práticas imitativas de profissionais da comunicação estão ligadas a posturas individuais e coletivas nas quais a cultura da organização comunicacional pode ser decisiva.

Lessig (2004) considera que as práticas imitativas na indústria da comunicação existem desde a sua formação. Afirma o autor que a indústria de Hollywood foi construída, em parte, de forma pirata quando compositores e diretores migraram da Costa Leste para a Califórnia no início do século XX para escapar ao controle das patentes de invenção cinematográfica atribuídas a Thomas Edison. Segundo o mesmo autor, a indústria da música norte-americana também se valeu da pirataria no início do século XX, quando a lei não exigia o pagamento de direitos autorais das reproduções na mídia, caso do rádio que também se beneficiou, logo no seu início, dessa estratégia. Ainda nos Estados Unidos, quando os empresários da tevê a cabo começaram a distribuir o sinal em 1948, muitos recusaram a pagar a retransmissão de conteúdos.

Muitas estratégias de imitação estão ligadas ao mercado concorrencial, caso da "estratégia imitativa" (TIGRE, 2006) e da "estratégia de imitação" (ROBBINS, 1998). Kotler e Keller (2006, p. 356) citam a "adaptação” como uma estratégia de marketing em que "o adaptador melhora ou adapta os produtos 
da líder". Os autores denominam "estratégias de seguidora de mercado" as empregadas por empresas que tentam abocanhar mercado de marcas líderes. Nesse contexto apontam quatro estratégias: falsificação; clonagem; imitação; e adaptação. Carvalho (1998) chama de "clonagem das FMs" o padrão repetitivo que as rádios FMs da cidade de Salvador (BA) mantêm entre si ao oferecerem músicas semelhantes.

Levitt (2006) argumenta que, historicamente, empresas possuem comportamento imitativo, levando em conta que a inovação implica grandes investimentos. Assim, sugere para alguns tipos de empresas considerarem o uso da estratégia de "imitação inovativa" , em que a organização planeja e cria imitações. Rutherford et al (2000) afirmam que um competidor júnior, ao praticar uma estratégia imitativa, pode retirar parte do mercado de um competidor sênior. Mas perguntam: é esta imitação uma "imitação inovativa", como sugerida por Levitt, ou uma infração legal em relação ao trade dress sênior?

Segundo Schnaars (1997), boa parcela da imagem negativa dos produtos imitativos provém dos produtos falsificados. Porém, como afirma o autor, muitos procedimentos imitativos são legítimos, caso dos que legalmente transpõem elementos para produtos e serviços inovadores.

A presença do binômio imitação-inovação na cultura e estratégia organizacional é algo secular, processual e, portanto, passível de uma sistematização, o que pode ser traduzido na forma de modelos teóricos de imitação e inovação. O item seguinte mostra um modelo teórico que contempla tipologias de inovação e imitação. Para tanto utilizou modelos tradicionais de inovação com o intuito de sistematizar as tipologias de inovação e criar as tipologias de imitação no âmbito de organizações comunicacionais.

\section{TIPOLOGIAS DE INOVAÇÃO}

Verifica-se intensa contribuição da literatura acerca de modelos de inovação que, de uma forma ampla, podem se dirigir a três abordagens, ou seja: ser algo novo ou original (HARGIE; TOURISH, 1996); ser um aperfeiçoamento ou uma mudança do que já existe (PUERTO, 1999); ou ainda ser algo percebido socialmente como novo (ROGERS 2003). Há autores que preferem uma composição híbrida, caso de ser algo novo ou aperfeiçoamento de processos ou produtos (ALENCAR, 1995; TIGRE, 2006). Com base nessa abordagem, sugere-se a seguir um modelo de inovação aplicável às organizações comunicacionais.

1 Levitt idealizou esse conceito originariamente no artigo "Innovative imitation" (LEVITT, 1966, p. 63-70). 


\section{Inovação intrínseca}

Entende-se por "inovação intrínseca" a inovação que envolve tanto a oferta de algo intrinsecamente novo quanto a remodelação inovadora do que existe, independentemente de como é observado pelas pessoas (ALENCAR, 1995; TIGRE, 2006), caso de uma campanha promocional original (ou obra-referência). Para exemplificar a prática da "inovação intrínseca" no campo da comunicação, talvez o Clube de Criação de São Paulo ${ }^{2}$ seja um bom referencial. A entidade, fundada em 1975, até 2009 publicou 34 nos quais são apresentados anúncios e campanhas promocionais premiados pela inovação e criatividade.

Obras de comunicação (anúncios publicitários, matérias jornalísticas, programas de televisão etc.) têm sido analisadas sob o aspecto da inovação-imitação e, comumente, essa análise se reporta ao uso ou à apropriação de "ideias". Mas Read (1981) argumenta que a ideia não pode ser copiada: somente sua expressão pode sê-lo, ou seja, sua manifestação ou expressão materializada na forma de texto, imagem ou objeto. Gombrich (1986) oferece vários exemplos no sentido de que uma mesma ideia inspiradora (uma paisagem, uma edificação urbana) deu origem a diferentes trabalhos sem que estes pudessem ser considerados imitações entre si.

Para corroborar essa visão, Paranaguá e Branco (2009) afirmam que ideias não são protegidas por direito autoral. Para explicar, citam uma obra literária que girou em torno de um menino náufrago convivendo no seu bote com um felino selvagem; vinte anos após, outro escritor usou essa ideia e não foi alvo de um processo por plágio. Os autores apresentam a conclusão de que a semelhança de ideias não configura, por si, um plágio, a não ser que diversos elementos partícipes das duas obras sejam similarmente caracterizados. Para isso citam a condenação por plágio, na França, de um filme que usou diversos elementos da obra cinematográfica $E$ o vento levou, caso de parte do enredo, certas características dos personagens, situações similares, algumas cenas e momentos dramáticos.

Essa premissa também está contida no artigo $8^{\circ}$ da Lei de Direitos Autorais (9.610), na qual não são objetos de proteção, enquanto direito autoral, ideias em si, mas apenas seu aproveitamento industrial ou comercial. Tal entendimento é particularmente importante no âmbito publicitário, em que se usam os termos "ideia” (CAPPO, 2003), “insight” (BERTOMEU, 2002) ou ainda "conceito" (TELLES, 2007) para designar a concepção criativa de obra, anúncio, slogan ou campanha que, como visto, não pode ser alvo de proteção.

2 Site do Clube de Criação de São Paulo. Dispoonível em: <http://ccsp.com.br/anuarios/anuarios. php?ano=34>. Acesso em: 30 abr. 2010. 


\section{Inovação percebida}

Para Havelock (1973, p. 4), a inovação deve ser vista sob a perspectiva de mudanças e de quem é alvo dela: "[...] qualquer mudança que representa algo novo para quem está sendo mudado”. Tal enfoque é compartilhado por Rogersv(2003, p. 12): "Uma inovação é uma ideia, prática ou objeto que é percebido como novo por uma unidade de adoção individual ou qualquer outra"’,

Portanto, uma inovação seria consequência de sua existência social na forma de notícia, propaganda, comercialização ou outras formas de difusão. A "inovação percebida" é dependente da difusão da inovação, pois a percepção somente pode ser obtida após alguma comunicação.

Há de se considerar, nesse conceito, que um produto pode ser inovação para um grupo e não sê-lo para outro, caso da experiência de telejornal da emissora Al Jazeera que, embora utilizasse um padrão jornalístico de televisão conhecido no Ocidente, revelou-se revolucionária para boa parte da população do Oriente Médio (ZAYANI, 2005).

A área publicitária oferece um outro exemplo: a Associação Brasileira de Propaganda (ABP) apurou que $77 \%$ das pessoas ficam sabendo da existência de produtos/marcas por meio das propagandas ${ }^{4}$, o que também é forte indício de que o próprio anúncio foi novidade. Um outro estudo elaborado pelo Ibope para a mesma ABP, em 2009, apurou que $71 \%$ dos entrevistados acreditam que a propaganda tornou-se mais inovadora ${ }^{5}$.

\section{Inovação conjugada}

Trata-se da inovação caracterizada pela oferta de algo novo ou remodelado e pela apropriação social como tal. Essa tipologia de inovação seria pautada pela percepção de algo como novo de forma que se trate também de uma inovação intrínseca, caso de ações de marketing ao lançar produtos, serviços e marcas a um mercado; ou então programas de difusão de inovação para comunidades e sociedades, caso da difusão de novas tecnologias para certos grupos sociais.

O atributo conjugado da inovação também decorre de ser, em muitos casos, um fenômeno coletivo e interativo, de forma que o receptor da inovação pode

3 Tradução livre nossa.

4 Estudo "A imagem da propaganda no Brasil", realizado em 2004. Pesquisa encomendada ao lbope pela ABP. Disponível em: <http://www.ibope.com.br/opiniao_publica/downloads/opp563_imagem_propaganda_abr05 >.pdf. Aceso em: 11 abr. 2010.

5 Pesquisa "Como o brasileiro percebe e avalia a propaganda". Ibope: população brasileira faz avaliação positiva da publicidade e reconhece seu papel na sociedade. Site do Grupo de Mídia-Rio de Janeiro. Rio de Janeiro, 12 abr. /2010. Disponível em: < http://www.midiarj.org.br>. Acesso em: 13 abr. 2010. 
participar de inovações futuras. Nesse sentido, o produto inovador não pode ser dissociado do contexto social e de sua respectiva difusão.

O marketing with defende o envolvimento do consumidor na cocriação do produto ou serviço, mesmo no caso de uma campanha de comunicação. Estudo de Bughin et al. (2008) aponta trabalhos de cocriação na área de marketing, caso da campanha que a Peugeot fez em 2007, para a qual convidou pessoas com o objetivo de contribuírem com sugestões para o design do carro utilizando a internet como plataforma, ação que atraiu quatro milhões de page views. os autores mostram pesquisa em que $60 \%$ dos entrevistados estariam dispostos a experimentar a cocriação e que a afinidade com a marca é o fator mais motivador.

A cocriação (open innovation ou networking innovation) pode ocorrer não somente entre consumidor e empresa, mas também com fornecedores e parceiros (PAQUETTE, 2006), algo análogo com o que ocorre em uma agência de comunicação, na qual redatores, diretores de arte, anunciantes e até fornecedores participam da elaboração da campanha.

\section{TIPOLOGIAS DE IMITAÇÃO}

Diferentemente do que tem ocorrido com o conceito de inovação, não estão evidenciados na literatura científica modelos tipológicos para imitação. No entanto, foi possível constatar que imitação e inovação são inversamente correspondentes e complementam-se na oferta de processos, produtos e obras. Essa constatação (de complementação e correspondência) advém de argumentos que sustentam ser a imitação um estágio natural da inovação (GANZ, 1980), que a inovação retoma a imitação para apresentar algo novo (OSÓRIO, 1992) e que as organizações se valem da convivência de estratégias inovadoras e imitativas (LEVITT, 2006).

Portanto, um ajuizamento correlato em relação à inovação permite categorizar a imitação em: a) intrínseca (imitação estética ou processual); b) percebida (o status de imitação depende de esta ser percebida como tal); c) conjugada (obra, produto ou processo similar percebido como imitação).

\section{Imitação intrínseca}

Decorre da cópia ou transposição total ou parcial de processos, obras ou produtos. O gênero telenovela, por exemplo, vale-se de uma série de estruturas e recursos estéticos copiados ano a ano de versões do passado e que servem de matrizes para as próximas seriações.

O discurso publicitário possui similaridades quando se consideram anúncios de determinadas categorias de produtos, como cervejas, automóveis e eletro- 
domésticos. Apresentam padrões similares por meio de elementos estéticos comuns, caso da presença de produto, marca, situações de consumo semelhantes, cenas de humor parecidas etc. Segundo Cappo (2003, p. 82), a propaganda se tornou mais homogeneizada: "Qualquer agência pode aproveitar ideias e técnicas de outras agências - e é o que normalmente fazem”.

A imitação do branding decorre de uma estratégia de marketing baseada na utilização de similaridades na embalagem, no design, nome da marca e na publicidade (ASTOUS; GARGOURI, 2001). Ações como esta coexistem com estratégias de comunicação de marketing que provocam confusão nos consumidores (MITSCHELL; PAPAVASSILIOU, 1999) fazendo-os adquirir inadvertidamente bens inferiores. Pereira (2001) denomina "publicidade confusória" aquela que confunde os consumidores quando concorrentes se valem de imitação de elementos distintivos; essa situação caracteriza-se por três fatores: anterioridade; existência de imitação; aptidão para estabelecer confusão. A publicidade confusória tem seu êxito dependente do conhecimento de elementos anteriores utilizados na comunicação, mas que não são percebidos no anúncio observado.

Mesmo legítimas ou não percebidas como imitação, as práticas imitativas têm sido alvo de crítica na sociedade contemporânea no sentido de repetir conhecimentos, pasteurizar modelos, homogeneizar produtos, empobrecer o universo cultural e servir como parâmetro educacional inadequado na formação de pensadores, cidadãos e profissionais.

\section{Imitação percebida}

A imitação percebida ocorre quando o repertório cognitivo de pessoas e grupos indica que um trabalho está se replicando de forma similar, o que os faz perceber como algo imitativo. Assim aconteceu, por exemplo, com músicas e programas de talk show; muitos telespectadores perceberam que programas de talk show brasileiros não eram criações nacionais (SILVA, 2009) e que músicas comercializadas como "lançamento" já o tinham sido feito anteriormente (SOUSA et al., 2009). A imitação, ao ser socialmente percebida, suscita polêmicas pela extensão ética, moral e legal.

A percepção de um trabalho de comunicação enquanto imitação tem causado reações negativas principalmente por parte daqueles que detêm os direitos sobre a obra-referência (TELLES, 2007). A percepção de imitação em conteúdos de comunicação, porém, parece merecer por parte dos consumidores menor atenção.

\section{Imitação conjugada}

Consiste no trabalho similar percebido como imitação. Essa percepção pode se dar por pessoas leigas, especialistas, autores ou outros públicos. No campo publi- 
citário, as paródias exemplificam imitações que são percebidas como tais, porém revestindo-se de um sentido jocoso e lícito (JOHNSON; SPILGER, 2000).

Lessig (2004) assinala que a imitação é necessária para a popularização do conhecimento e de técnicas. Cita o caso da fotografia e da máquina fotográfica que a partir do invento de Daguerre foi sendo aprimorada com aperfeiçoamentos até chegar com Eastman a um barateamento e consequente uso generalizado, inclusive por amadores. O autor considera que o estreito e imponderável combate à imitação, inclusive por meios legais, é contrário à livre cultura.

No âmbito negativo, a imitação conjugada pode estar associada à imitação de objetos, serviços e obras que afrontam parâmetros legais, desrespeitam direitos, trazem danos sociais. Constitui-se em ação deliberada de pessoas e organizações para obter vantagens ilícitas às custas do trabalho e do investimento de terceiros.

Lewis (2007) sustenta que a prática do plágio no jornalismo não é apenas uma violação ética individual, mas algo que permeia a ideologia profissional; apurou que o plágio é prática recorrente até em grandes veículos. Para o autor, o plágio mascara a recusa de admitir que o jornalismo é construído também em cima da cópia e imitação, caso de reproduções de textos da internet.

Porém, faz parte da rotina das organizações jornalísticas comprar e replicar de forma lícita textos e material noticioso de agências de notícias e até de outros jornais, prática esta atrelada a contratos legais e formalmente estabelecidos.

Muitas vezes, um fato é acompanhado por vários repórteres (entrevista coletiva, relato de acidente etc.), sendo as informações compartilhadas e homogeneizadas na linguagem da imprensa, algo que possibilita a percepção equivocada de tratar-se de prática imitativa.

Para evitar condutas incorretas, alguns setores da indústria da comunicação estipulam em seus códigos de ética profissional diretrizes e orientações quanto a práticas imitativas, caso do Código de Ética dos Jornalistas Brasileiros e do Código do Radialista.

A indústria da comunicação, segundo Naim (2006), também participa do mercado ilegal da imitação, caso de instrumentos de comunicação utilizados para promover marcas piratas ao mercado.

Nesse processo, há também a conivência dos consumidores que, conscientemente ou não, adquirem imitações de marcas e bens face à avaliação do custobenefício (DEBORD, 1997). Tal rede de imitações conta com estrutura mercadológica à altura da legalmente instalada utilizando, por exemplo, internet e folhetos. Porém, tal rede evita utilizar os meios de comunicação de massa, dada a visibilidade que teria perante autoridades, empresas copiadas e consu- 
midores conscientes. Carvalho (2006) argumenta que o ramo da ilegalidade tem a promoção de seus trabalhos, produtos e marcas sustentada pela ação da comunicação boca a boca.

\section{CONSIDERAÇÕES FINAIS}

Este artigo teve por objetivo propor um modelo teórico para a prática da imitação-inovação no contexto organizacional, tendo como foco o campo da comunicação.

A proposta do modelo foi antecedida pela análise do referencial teórico, mostrando que estratégias, cultura e processos das organizações comunicacionais apresentam posturas de inovação e imitação, as quais podem apresentar desdobramentos positivos e negativos, extensivos aos seus produtos.

O modelo fixa três tipologias de inovação: inovação intrínseca; inovação percebida; e inovação conjugada. Ele foi sistematizado com base em considerável referencial teórico disponível. Mas teve que ser construído a partir de uma similaridade com o modelo de inovação. Essa similaridade ocorreu por serem imitação e inovação elementos inversamente correspondentes (espelhados) quando considerados em uma base comparativa (processos, produtos, obras), porém complementares por se nutrirem um ao outro.

Foi relevante constatar que o modelo proposto pode ser exercitado com as práticas das organizações comunicacionais, um dos propósitos deste estudo.

Por ser de âmbito exploratório, a investigação aqui apresentada é limitada, fazendo-se necessário que outros modelos teóricos possam ser apresentados para ampliar a qualidade e profundidade sobre os aspectos da imitação-inovação nas organizações comunicacionais.

\section{REFERÊNCIAS}

ALENCAR, Eunice M .L.S. Criatividade. Brasília: Editora UnB, 1995.

ASTOUS, Alain; GARGOURI, Ezzedine. Consumer evaluations of brand imitations.

European Journal of Marketing, v.35, n. 1-2, p. 153-167, 2001.

BERTOMEU, João V. Cegato. Criação na propaganda impressa. São Paulo: Futura, 2002.

BUGHIN, Jacque; CHUI, Michael; JOHNSON, Brad. The nest step in open innovation. The McKinsey Quarterly, June 2008.

CAPPO, Joe. 0 futuro da propaganda. São Paulo: Cultrix, 2003.

CARRASCOZA, João Anzanello. Do caos à criação publicitária: processo criativo, plágio e ready-made na publicidade. São Paulo: Saraiva, 2008.

CARVALHO, Arilson. 0 impacto negativo da pirataria no cenário mercadológico e as dificuldades no combate a falsificação. Revista do Ibrac, São Paulo, Instituto Brasileiro de Estudos de Concorrência, Consumo e Comércio Internacional, v. 12, n. 3, p. 47-84, 2006 
CARVALHO, Enio. Marketing: aprendendo com os erros e acertos. São Paulo: Makron, 1998.

DAY, Louis A. Ethics in media communications: cases and controversies. Belmont: Wadsworth, 1991.

DEBORD, Guy. A sociedade do espetáculo. Rio de Janeiro: Contraponto, 1997.

GANZ, Carole. Review essay: linkages between knowledge creation, diffusion, and utilization. Science Communication, v.1, n. 4, p. 591-612, June 1980.

GOMBRICH, Ernst Hans. Arte e ilusão: um estudo da psicologia da representação pictórica. São Paulo: Martins Fontes, 1986.

HARGIE, Colin; TOURISH, Dennis. Corporate communication in the management of innovation and change. Corporate Communications, Bradford. v. 1, n. 2, p. 3-12, 1996.

HAVELOCK, Ronald G. The change agent's guide to innovation en education. Englewood, NJ: Educational Technology Publications, 1973.

JOHNSON, Madeline; SPILGER, Ursula. Legal considerations when using parodies in advertising. Journal of Advertising, v. 29, n. 4, p. 77-86, Winter 2000.

KOLTER, Philip; KELLER, Kevin Lane. Administração de marketing. São Paulo: Prentice Hall, 2006.

LESSIG, Lawrence. Free culture: how big media uses technology and the law down culture and control creativity. Londres: Penguin, 2004.

LEVITT, Theodore. Ted Levitt on marketing: a Harvard business review paperback. Boston: Harvard Business School Publishing, 2006.

. Innovative imitation. Harvard Business Review, p. 63-70, Sept./Oct. 1966.

LEWIS, Normam P. Paradigm disguise: systemic influences on newspaper plagiarism. Tese (Doutorado em Filosofia) - Faculty of the Graduate School of the University of Maryland, 2007.

MACMILLAN, Fiona. Is copyright blind to the visual? Visual Communication, v. 7, n. 97, 2008. Disponível em: <http://vcj.sagepub.com/cgi/content/abstract/7/1/97>. Acesso em: 18 nov. 2008.

MATTELART, Armand. A globalização da comunicação. Bauru: Edusc, 2002.

MITSCHELL, Vincent-Wayne; PAPAVASSILIOU. Marketing causes and implications of consumer confusion. Journal of Product $\&$ Brand Management, V. 8, n. 4, p. 319-342, 1999.

NAIM, Moisés. Ilícito: 0 ataque da pirataria, da lavagem de dinheiro e do tráfico à economia global. Rio de Janeiro: Zahar, 2006.

OSÓRIO, Luiz Carlos. 0 ponto de vista evolutivo: ponte epistemológica entre a imitação e a criação. Revista Brasileira de Psicanálise, São Paulo, Associação Brasileira de Psicanálise, v. 26, n. 4, p. 505-514, 1992.

PAQUETTE, Scott. Customer knowledge management. Toronto: University of Toronto, Idea Group Inc., 2006.

PARANAGUÁ, Pedro; BRANCO, Sérgio. Direitos autorais. Rio de Janeiro: Editora FGV, 2009.

PEREIRA, Marco A. Marcondes. Concorrência desleal por meio da publicidade. São Paulo: Ed. Juarez de Oliveira, 2001.

PUERTO, Henry B. Design e inovação tecnológica: coletânea de ideias para construir um discurso. Salvador: IEL/Programa Bahia Design, 1999.

READ, Herbert. As origens da forma na arte. Rio de Janeiro: Zahar, 1981.

ROBBINS, Stephen P. Organizational behavior: concepts, controversies, applications. New York: Prentice Hall, 1998.

ROGERS, Everett. Diffusion of innovation. New York: Free Press, 2003.

RUTHERFORD, Denney G.; PERKINS, Andrew W.; SPANGENBERG, Eric R. S. Trade dress and consumer perception of product similarity. Journal of Hospitality \& Tourism Research, International Council on Hotel, Restaurant and Institutional Education, v. 24, n. 2, p. 163-179, maio 2000,

SCHNAARS, Steven P. Administrando as estratégias da imitação. São Paulo: Pioneira, 1997.

SILVA, Fernanda Maurício. Talk show: um gênero televisivo entre o jornalismo e o entretenimento. E-Compós - Revista da Associação Nacional dos Programas de Pós-Graduação em Comunicação, Brasília, v.12, n.1, jan./abr. 2009.

SOUSA, Diogo Araújo et al. De quem é essa música? Influência social e avaliação artística. Mosaico: estudos em psicologia. Belo Horizonte, Curso de Psicologia da Faculdade de Filosofia e Ciências Humanas da UFMG, v. III, n. 1, p. 1-14, 2009.

TELLES, Cecilia C. Prado. As questões éticas da propaganda: um estudo com profissionais de agências de propaganda. 2007. Dissertação de mestrado (Administração) - São Paulo: Centro Universitário Nove de Julho. 
TIGRE, Paulo B. Gestão da inovação: a economia da tecnologia no Brasil. Rio de Janeiro: Elsevier, 2006.

UTTERBACK, James M. Dominando a dinâmica da inovação. Rio de Janeiro: Qualitymark, 1996.

WHITE, J. William. A communication model of conceptual innovation in science. Communication Theory, 0xford, v. 11, n. 3 p. 290-314, Aug. 2001.

ZAYANI, Mohamed. The Al Jazeera phenomenon: critical perspectives on new Arab media. Sidmouth (UK): Pluto Press, 2005.

Recebido em: 04.07.2010 / Aceito em: 29.09.2010 